\title{
Simulation of Offshore Wind Turbine Link to the Electric Grid through a Four-Level Converter
}

\author{
Mafalda Seixas $^{1,2,3}$, Rui Melício ${ }^{1,3}$, and Victor M.F. Mendes ${ }^{1,2}$ \\ ${ }^{1}$ Universidade de Évora, Évora, Portugal \\ mafalda.seixas@gmail.com, ruimelicio@uevora.pt \\ ${ }^{2}$ Instituto Superior de Engenharia de Lisboa, Lisbon, Portugal \\ vfmendes@deea.isel.pt \\ ${ }^{3}$ IDMEC/LAETA, Instituto Superior Técnico, Universidade de Lisboa, Lisbon, Portugal
}

\begin{abstract}
This paper is on the modulation of offshore wind energy conversion systems with full-power converter and permanent magnet synchronous generator with an AC link. The drive train considered in this paper is a threemass model which incorporates the resistant stiffness torque, structure and tower, in the deep water, due to the moving surface elevation. This moving surface influences the current from the converters. A four-level converter is considered with control strategies based on proportional integral controllers. Although more complex, this modulation is justified for more accurate results.
\end{abstract}

Keywords: Collective awareness, offshore wind turbine, multibody drive train, four-level converter, simulation.

\section{Introduction}

The demand for energy, the shortage of fossil fuels and the need for carbon footprint reduction have resulted in a global awareness of the importance of energy savings and energy efficiency [1]. The wind power industry and the construction of wind farms are undergoing rapid development [2], [3]. The installations and operation cost of OWT are still more expensive than that of onshore wind turbine, but an OWT situated sufficiently far away from the coast can capture more wind energy and will have a longer operation life [4], [5]. Offshore locations offer a number of advantages compared with onshore including a smoother, less turbulent wind and the ability to build larger turbines due to reduced concerns over visual impact [6]. Offshore floating structures are influenced by marine waves in coastal waters [7]. The coupling effect of the wind and wave dynamics are considered as an effect of the floating support structure motion on the blades and the shaft, as well the inertia induced by the motion of the blades [4]. The offshore wind energy conversion to mechanical energy over the rotor of an OWT is influenced by various forces acting on the blades and on the tower, i.e., centrifugal, gravity and varying aerodynamic forces acting on blades, gyroscopic forces acting on the tower and also by hydrodynamics depending on the foundation system and deep water. Consequently, the past experience gained regarding onshore wind turbines is not enough to be applied without further consideration to the development of OWT [8]. 
As wind energy is increasingly integrated into an electric grid, electric energy quality is becoming a concern of utmost importance, not only the stability of already existing power systems but also the total harmonic distortion (THD) must be assessed in order to ensure enough quality on the energy injected into the grid [9]. Some papers have been issued on OWT models, but mainly using simplified models to describe the drive train, the power converter or the control strategies. However, the increased wind power penetration, as nowadays occurs in Portugal, requires new models and system operation tools.

In this paper, an offshore variable-speed wind turbine in deep water is considered equipped with a permanent magnet synchronous generator (PMSG) using a full power converter, namely a back-to-back four-level converter topology, converting the energy of a variable frequency source in injected energy into the grid with constant frequency through an AC link. Although not imposed for OWT, the IEEE-519 imposes a THD not exceeding 5\%. This THD limit is followed as a guideline for the filter design. The drive train considered is described by a three-mass model with an input stiffness torque due to the need to take in consideration the effects of the moving floating surface. The moving floating surface is modeled by one mass describing the tower and the floating structure. As a new contribution to earlier studies, a more realistic modeling of OWT with a complex multibody drive train is presented combined with a complex control strategy, and comprehensive simulation studies are carried out in order to adequately assert the system performance.

\section{Relationship to Collective Awareness Systems}

Awareness in a business reality implies a clear understanding of the enterprise, the operational context, the opportunities and risks: in essence, awareness in a business represents a solid base for sustainable enterprise competitiveness and acceptance of sustainability ideas. A collective awareness system (CAS) can thus be seen as a sociotechnical artifact capable of openly linking objects, people, processes and knowledge for the benefit of the enterprise, and the society at large. Despite the marked social nature of this CAS is necessary public investment and advanced technological research [10]. Public investment and advanced technological research is critical to the still-emerging offshore business wind industry, the projects are expensive [11] and has a need to be supported by social acceptance. The awareness enabled by such a system can have very concrete impacts, for instance in empowering and motivating citizens to make informed decisions as consumers, or in fostering collective environmentally-savvy behavioral changes and a more direct democratic participation [12], regarding environmental and conversion of energy from alternative sources into electrical energy, ensuring sustainability. Only with a clear awareness of environmental problems will the people support their government's policies of investment in research in renewable energy, such as OWT. In this sense the creation of CAS supports the continuation of those policies which in turn supports the research in this area. Another important aspect in the creation of CAS is the dissemination of data on real physical systems that support the creation of mathematical models, as used in this work, closer to reality, thus allowing the study of concrete solutions. 


\section{$3 \quad$ Modeling}

The configuration of the simulated WOT system with a four-level converter is shown in Fig. 1.

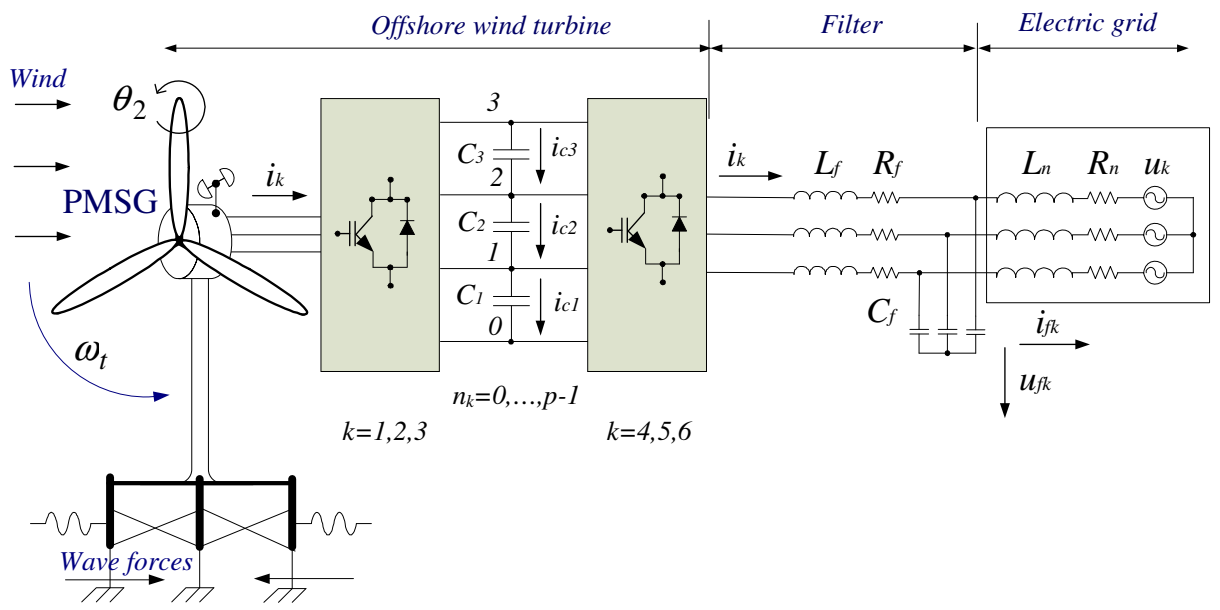

Fig. 1. OWT with back-to-back four-level converter

The configuration of the simulated drive train is shown in Fig. 2.

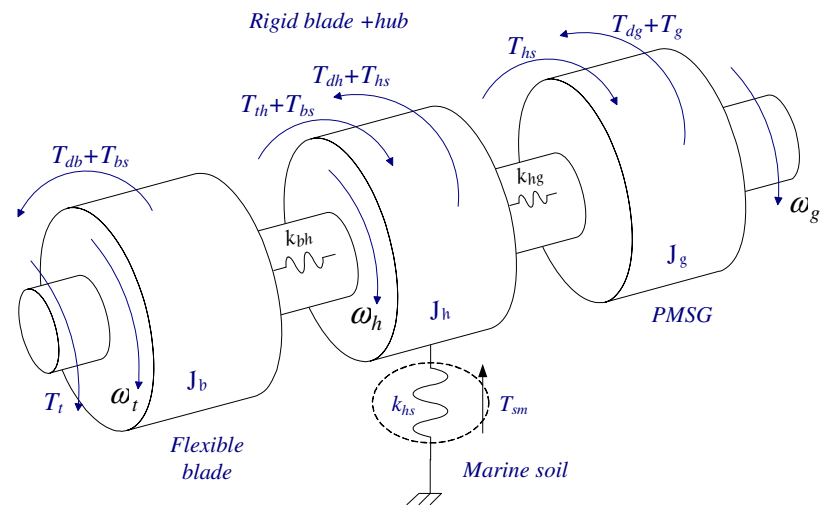

Fig. 2. OWT drive train

The modeling details regarding the wind speed, the wind turbine, the drive train can be seen, for instance, in [9]. The equations for modelling a PMSG are given by:

$$
\begin{gathered}
d i_{d} / d t=1 / L_{d}\left(v_{d}+p \omega_{g} L_{q} i_{q}-R_{d} i_{d}\right) \\
d i_{q} / d t=1 / L_{q}\left[\mathrm{v}_{q}-p \omega_{g}\left(L_{d} i_{d}+M i_{f}\right)-R_{q} i_{q}\right]
\end{gathered}
$$


where $i_{d}, i_{q}$ are the stator dq currents, $i_{f}$ is the equivalent rotor current, $L_{d}, L_{q}$ are the stator inductances, $M$ is the mutual inductance, $R_{d}, R_{q}$ are the stator resistances, $v_{d}, v_{q}$ are the stator voltages, $p$ is the number of pair of poles, $\omega_{g}$ is the generator rotor speed. Due to the consideration of avowing demagnetization of the permanent magnet in the PMSG [9], a null stator current $i_{d}=0$ has to be imposed.

The back-to-back four-level converter is an AC-DC-AC converter having eighteen unidirectional commanded IGBT's $S_{i k}$ used as a rectifier, and with the same number used as an inverter. The rectifier is connected between the PMSG and a capacitor bank. The inverter is connected between this capacitor bank and a second order filter, which in turn is connected to an electric grid. The groups of six IGBT's linked to the same phase constitute the leg $k$ of the converter. The converter has $p=4$ levels. The voltage level is associated with the auxiliary variable $n_{k}$ which range from 0 to $(p-1)$, used in the calculation of the $u_{s k}$ generator output voltage. The voltage $u_{s k}$ as a function of $p$ and $n_{k}$ is given by:

$$
u_{s k}=\frac{1}{3} \frac{1}{(p-1)}\left(2 n_{k}-\sum_{\substack{i=1 \\ i \neq k}}^{3} n_{i}\right) v_{d c} \quad k \in\{1,2,3\} .
$$

The current on each capacitor bank $i_{c j}$ is given by:

$$
i_{c j}=\sum_{k=1}^{3} \delta_{n k} i_{k}-\sum_{k=4}^{6} \delta_{n k} i_{k} \quad j \in\{1, \ldots, p-1\}
$$

where

$$
\delta_{n k}=\left\{\begin{array}{ll}
0 & j>n_{k} \\
1 & j \leq n_{k}
\end{array} .\right.
$$

The voltage $v_{d c}$ is modeled by the state equation given by:

$$
\frac{d v_{d c}}{d t}=\left(\sum_{j=1}^{p-1} \frac{1}{C_{j}} i_{c j}\right)
$$

A three-phase symmetrical circuit in series models the electric grid. The state equation for the injected current in the electrical grid is given by:

$$
\frac{d i_{f k}}{d t}=\frac{1}{L_{n}}\left(u_{f k}-R_{n} i_{f k}-u_{k}\right) \quad k=\{4,5,6\}
$$

where $L_{n}$ and $R_{n}$ are the electrical grid inductance and resistance, respectively, $u_{f k}$ is the voltage at the filter, $u_{k}$ is the voltage at the electric grid. 


\section{Control Method}

The PI controllers are used for the control of the OWT. Pulse modulation by space vector modulation associated with sliding mode is used for controlling the converters. The sliding mode control is important for controlling the converters, by guaranteeing the choice of the most appropriate space vectors [9]. The power semiconductors present a finite switch frequency. Thus, for a value of the switching frequency, an error $e_{\alpha \beta}$ will exist between the reference value and the control value [9]. In order to guarantee that the system slides along the sliding surface $S\left(e_{\alpha \beta}, t\right)$ is necessary that the state trajectory near the surfaces verifies in accordance with the stability condition [9] given by:

$$
S\left(e_{\alpha \beta}, t\right) \frac{d S\left(e_{\alpha \beta}, t\right)}{d t}<0
$$

A small error $\varepsilon>0$ for $S\left(e_{\alpha \beta}, t\right)$ exists in practice. Hence, the strategy is given by:

$$
-\varepsilon<S\left(e_{\alpha \beta}, t\right)<+\varepsilon .
$$

Strategy (9) is taken by hysteresis comparators. The output voltage for each converter leg has four possible values $\left(0, \frac{1}{3} v_{d c}, \frac{2}{3} v_{d c}, v_{d c}\right)$; therefore the three legs of the rectifier or of the inverter have sixty four possible combinations for the output voltages. The output voltage vectors in the $\alpha \beta$ coordinates for the four-level converter are shown in the Fig. 3.

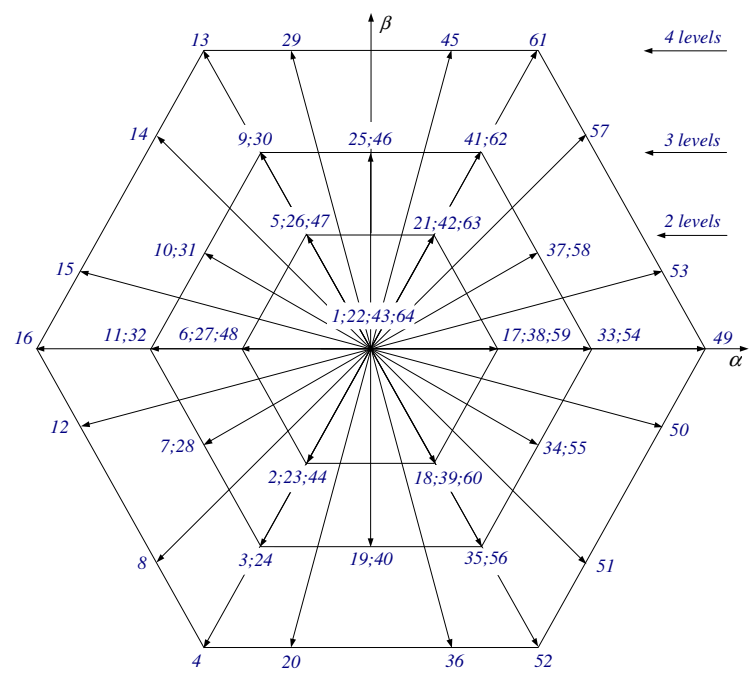

Fig. 3. Output voltage vectors for the four-level converter 
The comparison of $e_{\alpha}$ and $e_{\beta}$ errors with the values of the sliding surface $S\left(e_{\alpha \beta}, t\right)$ enables to find at each instant the variables $\sigma_{\alpha}$ and $\sigma_{\beta}$. The integer voltage variables $\sigma_{\alpha}$ and $\sigma_{\beta}$ satisfy the following condition $\sigma_{\alpha}, \sigma_{\beta} \in\{-3,-2,-1,0,1,2,3\}$. These variables allow choosing the most appropriate vector.

\section{Simulation}

The mathematical model for the OWT with the four-level converter topology was implemented in Matlab/Simulink. The wind speed profile is shown in Fig. 4.

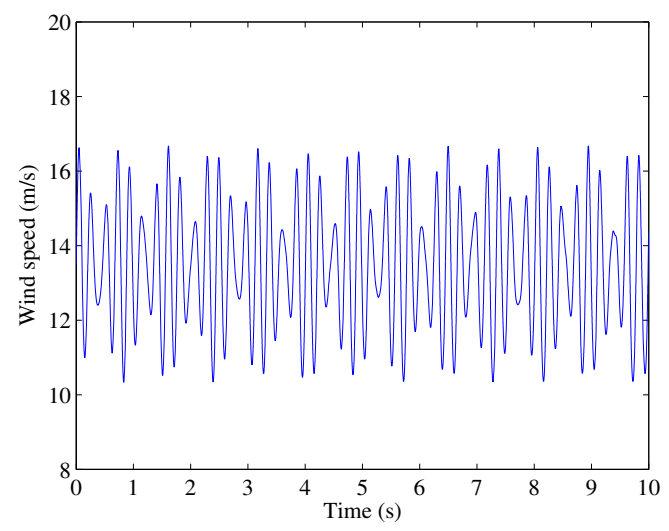

Fig. 4. Wind speed profile

The reference voltage and the voltage $v_{d c}$ is shown in Fig. 5.

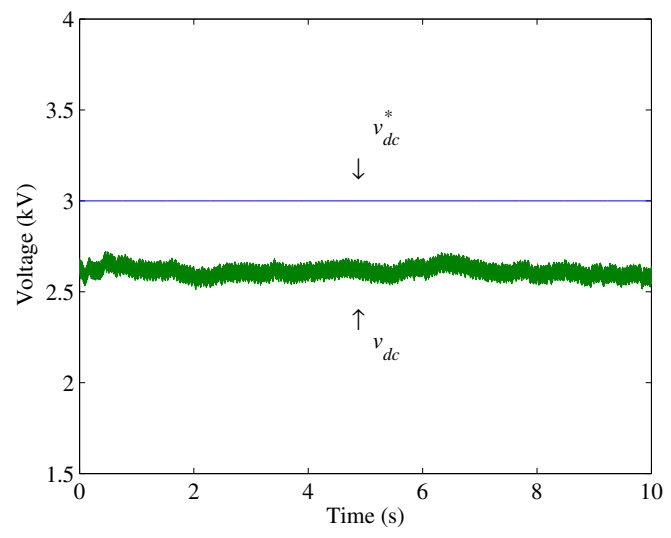

Fig. 5. The reference voltage $v_{d c}$ 
In Fig. 5, despite the wind speed profile the OWT system is capable of performing in a satisfactory manner, attenuating the influence of the wind speed on the system.

The instantaneous current injected in the electric grid is shown in Fig. 6.

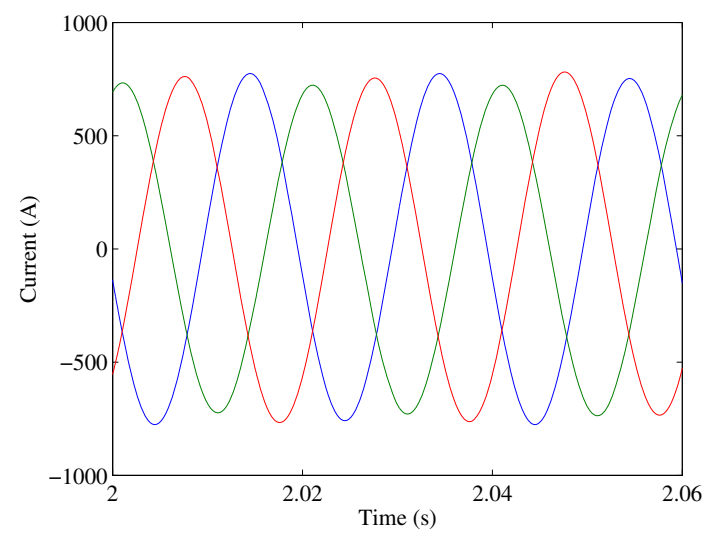

Fig. 6. Current injected in the electric grid

\section{Conclusion}

Europe has led offshore wind, for instance, due to the limited land available for onshore developments and so the offshore development is an actual option. Also offshore developments have a benefit in what regards the less variability and intermittence of the wind speed. The offshore wind energy conversion to mechanical energy over the rotor of an OWT is influenced by some actions different from the ones on onshore wind energy conversion systems, for instance, hydrodynamics depending on the foundation system and deep water, originating movements on the surface influencing the behavior of the output of the converters. Consequently, the past experience gained regarding onshore wind turbines has to be adapted and improved in order to be applied to OWT. One of the adaptations regards the modulation of wind energy conversion systems with full-power converter and permanent magnet synchronous generator with an AC link for offshore developments.

Hydrodynamics on OWT deserve to be considered in a manner to be more realistic to reveal the behavior of the output of the converters. So there is a justification for researching with a drive train with three-mass model.

Pulse width modulation by space vector modulation associated with sliding mode is used for controlling the converter. The voltages in the capacitor banks for the fourlevel converter should be as balanced as possible, but this is very challenging to do in a four-level converter. Hence, the control strategy proposes the use of four tables for selecting the convenient output voltage vector, achieving a better balanced for the capacitor banks voltages. A case study using Matlab/Simulink is presented for a fourlevel converter topology integrating wind power with the electrical grid. The simulation study revealed an overall good performance of the proposed OWT with the 
four-level converter. The wave form of the current injected in the electric grid seems purely sinusoidal, due to the strategy followed on the converters and the filtering used before the injection into the grid considered as a symmetric three phase sinusoidal voltage system.

Acknowledgments. This work was partially supported by Fundação para a Ciência e a Tecnologia, through IDMEC under LAETA, Instituto Superior Técnico, Universidade de Lisboa, Portugal.

\section{References}

1. Popovic-Gerber, J., Ferreira, J.A.: Power electronics for sustainable energy futurequantifying the value of power electronics. In: 3rd IEEE Energy Conversion Congress and Exposition, Atlanta, pp. 112-119 (2010)

2. Saheb-Koussa, D., Haddadi, M., Belhamel, M., Hadji, S., Nouredine, S.: Modeling and simulation of the fixed-speed WECS (wind energy conversion system): Application to the Algerian Sahara area. Energy 35, 4116-4125 (2010)

3. Fusco, F., Nolan, G., Ringwood, J.V.: Variability reduction through optimal combination of wind/wave resources - An Irish case study. Energy 35, 314-325 (2010)

4. Luo, N., Bottasso, C.L., Karimi, H.R., Zapateiro, M.: Semiactive control for floating offshore wind turbines subject to aero-hydro dynamic loads. In: International Conference on Renewable Energies and Power Quality - ICREPQ 2011, Las Palmas de Gran Canaria, pp. 1-6 (2011)

5. Musial, W., Butterfield, S., Boone, A.: Feasibility of floating platform systems for wind turbines. National Renewable Energy Laboratory - NREL/CP - 5oo-34874 (2003)

6. Wilkinson, M.R., Tavner, P.J.: Condition monitoring of wind turbine drive trains. In: 17th International Conference on Electrical Machines, Chania, pp. 1-5 (2006)

7. Holthuijsen, L.H.: Waves in Oceanic and Coastal Waters, pp. 145-196. Cambridge University Press, Cambridge (2007)

8. Bir, G., Jonkman, J.: Aeroelastic instabilities of large offshore and onshore wind turbines. Journal of Physics 75, 012069 (2007)

9. Melício, R.: Modelos dinâmicos de sistemas de conversão de energia eólica ligados à rede eléctrica: PhD Thesis: UBI/FE/DEE, Covilhã, Portugal (2010) (in Portuguese)

10. Future Internet Enterprise Systems, http://www.fines-cluster.eu/fines/jm/ Documents / Download-document/410-FInES-Horizon-2020_PositionPaper-v2.00_Annex.html

11. Offshore Wind in Europe: Lessons for the US, http://theenergycollective.com/ lewmilford/282836/offshore-wind-europe-lessons-us

12. Digital Agenda For Europe, http: / / ec . europa.eu/digital-agenda/en/ collective-awareness-platforms-sustainability-and-socialinnovation 